\title{
ТЕОРЕТИЧЕСКИЕ И ПРАКТИЧЕСКИЕ ПОДХОДЫ К ОПРЕДЕЛЕНИЮ ОСОБЕННОСТИ ПСИХОЛОГИЧЕСКОЙ ПОМОЩИ ЖЕНАМ ПОГИБШИХ ПРАВООХРАНИТЕЛЕЙ ПРИ УТРАТЕ
}

Рыбык Л. А., аспирант

Украина, г. Киев. Национальная академия внутренних дел.

DOI: https://doi.org/ 10.31435/rsglobal_ws/30112018/6238

\section{ARTICLE INFO}

Received: 05 September 2018

Accepted: 27 November 2018

Published: 30 November 2018

\section{KEYWORDS}

loss,

grief,

emergency,

extreme psychology,

crisis intervention,

stress factors.

\begin{abstract}
The preambule gives the reasons for the relevance of the problem of experiencing the loss and grief of the perished law enforcers' wives in Ukraine, providing them with psychological counseling and the necessary psychological assistance based on the modern scientific heritage, world and local practical experience. The aim of the study is to examine the theoretical and practical approaches of providing psychological assistance to widows, as well as to analyze the impact of psychological assistance on the overall level of adaptive grieving.

The main part reveals the main theoretical and practical approaches to the definition of varieties, structure and content of systemic psychological support based on extreme psychology and crisis intervention. It was noted the necessity of providing emotional support and psychological assistance at the early stages of experiencing grief and loss. It presents the brief description of the factors influencing psychological state of the person, who is in an emergency situation - the sudden death of a loved one.

The concept of adaptive and non-adaptive ways of responding to stress factors, based on a study by E. Lindemann, is considered. Psychological reactions are described that correspond to different phases of a crisis state after a traumatic event, accordingly to the studies of D. Aguilera and J. Messick. The results of a comparative experimental psychological examination of the perished law enforcers ' wives are set out in order to determine the significance of individual factors of socio-psychological adaptation for the formation of effective psych correctional programs. Statistically reliable data on the impact of psychological support on the general level of socio-psychological adaptation are obtained. In conclusion, it is stated the reasonability of providing the psychological assistance in case of loss, taking into account the hierarchy of personal problems. Experimentally proven that, when providing systemic psychological assistance, there is a tendency towards to of adaptability and emotional comfort indicators, decrease of level and moving away from problem situations avoidance.
\end{abstract}

Citation: Рыбык Л. А. (2018) Teoreticheskie i Prakticheskie Podhodi k Opredeleniyu Osobennosti Psihologicheskoi Pomoschi Jenam Pogibshih Pravoohranitelei pri Utrate. World Science. 11(39). doi: 10.31435/rsglobal_ws/30112018/6238

Copyright: (C) 2018 Рыбык Л. А. This is an open-access article distributed under the terms of the Creative Commons Attribution License (CC BY). The use, distribution or reproduction in other forums is permitted, provided the original author(s) or licensor are credited and that the original publication in this journal is cited, in accordance with accepted academic practice. No use, distribution or reproduction is permitted which does not comply with these terms.

Постановка проблемы. Специфика работы в экстремальных условиях и непосредственное участие правоохранителей в боевых действиях остро поставили вопрос о эффективной психологической и социальной помощи сотрудникам Национальной полиции, Национальной гвардии, пограничников и других силовых структур, а также членам их семей, в 
том числе и женам погибших правоохранителей. В настоящее время исследования негативных психосоциальных последствий воздействия экстремальных событий свидетельствуют о наличии пограничных психических расстройств, аддиктивного поведения с формированием сопутствующих зависимостей, нарушения адаптивности, что выражается через депрессию, суицидальное поведение и тому подобное. Очевидна потребность в научно-прикладном осмыслении сущности и особенностей психологической помощи, как в экстремальной ситуации, так и при работе с ее последствиями.

Своеобразной категорией лиц, нуждающихся в психологической помощи, являются жены правоохранителей, погибших при исполнении служебных обязанностей. Женщины находятся в состоянии горя через невосполнимую утрату близкого человека, а внезапность события может стать причиной даже осложненного горя. Именно поэтому психическое состояние этих женщин вызывает вполне понятное беспокойство.

Анализ последних исследований и публикаций. Теоретическим и практически ориентированным исследованиям проблем психического состояния особ, которые переживают горе из-за потери близкого человека, посвящены работы известных отечественных и зарубежных ученых. Сегодня научный мир предлагает достаточно эффективные методы оказания психологической помощи людям, которые пережили травмирующие события. Основные аспекты оказания психологической помощи правоохранителям, военнослужащим, а также участникам боевых действий и их семьям отражены в трудах А. Блинова, Р. Кадырова, А. Караян, И. Липатова, И. Приходько, И. Сиромьятникова, Г. Тимченко, А. Тимченко, А. Харитонова, Л. Шестопаловой и др.

В частности, психологические последствия потери близкого человека в ракурсе жизненного кризиса рассмотрено О.Байером. В работах А. Моховикова акцентируются внимание на особенностях патологических реакций при синдроме потери. Тщательное исследование В. Уордена посвящено анализу функций и задач, которые присущи горю. Н.Тарабриною определены характеристики посттравматического стрессового расстройства как одной из реакций на травматическое событие. Психологические особенности переживания потери близкого человека, который профессионально работал в режиме высокого риска, исследованы М.Заворотной. Заслуживают также внимания практические рекомендации предоставление психосоциальной помощи при переживании горя, содержащиеся в работе Л. Вольновой.

Целью статьи является рассмотрение теоретических и практических подходов оказания психологической помощи супругам погибших правоохранителей, исследования влияния психологической помощи на общий уровень адаптивного переживания утраты.

Изложение основного материала и результатов исследования. Актуальность проблемы переживания горя обусловила проведение исследования особенностей психологической помощи при переживании потери. В качестве рабочего понятия, которое отражает практику психологической и социальной помощи, нами выбрана предложенное одним из ведущих специалистов в области практической психологии А. Бондаренко: «психологическая помощь является область и способ деятельности, предназначенные для содействия человеку и обществу в решении широкого круга проблем, порождаемых душевной жизнью человека в социуме» [2, с.12].

Вопрос выявления оптимальных методов, способов и приемов оказания психологической помощи имеют определенную историографию в психологической науке. Научно сформулировано представление о категории психологической помощи, которым оно остается до сих пор, принадлежит К. Роджерсу, одному из основателей экзистенциальной психологии и персонализма, и базируется на почве консультирования и психотерапии. Однако о необходимости оказания психологической помощи в сложных жизненных обстоятельствах говорится еще в работах Эпикура, который считал, что людям нужна поддержка «против страха внешних обстоятельств» [14]. Эту поддержку традиционно оказывают церковь и смежные с религией социальные институты. Согласно социокультурного контекста, под влиянием научных открытий и социальных изменений первой половины XX века, начинается гуманизация психиатрии и формируется фундамент для института психологической помощи. «В течение долгого периода сама идея психологической помощи включает в себя весь спектр возможных практик, направленных на исправление «психического нездоровья», «душевных» (психолого-психиатрических) нарушений личности - от психологического консультирования, которое зарождается, и психотерапии до любых форм психиатрического вмешательства» [5]. 
Учитывая современные политические и социальные условия жизнедеятельности общества в Украине, в психологической помощи нуждаются женщины, пережившие травмирующее событие потери мужа. Вместе с тем, необходимо отметить, что значительное количество стран придерживается принципа добровольного и сознательного обращения человека за помощью. Это объясняется стремлением невмешательства в личностный мир человека без его желания. Традиционно сложилось, что человеку надо побыть наедине со своими переживаниями. Однако подобная позиция не учитывает того факта, что женщина находится под влиянием чрезвычайной ситуации (в состоянии шока) и по большей части она лишена каких - либо знаний по поводу возможных психических реакций на травмирующее событие. То есть, она не может сознательно понимать и анализировать является ли то, что с ней происходит нормальным, или это относится к патологическим реакциям. Таким образом, перед женщиной одновременно возникают две проблемы - пережить потерю близкого человека и адаптироваться к новым условиям жизни.

Исходя из вышеуказанного, сущность и особенности психологической помощи супругам правоохранителей, погибших при исполнении служебных обязанностей, базируются на принципах экстремальной психологии, и имеют некоторые существенные отличия от привычного и общепринятого понимания оказания психологической помощи. А именно:

- экстремальные психологи не ждут, когда к ним придут за помощью - они сами предлагают свою помощь пострадавшим, которые в условиях чрезвычайной ситуации не осознают влияния ситуации на собственную психику;

- экстремальные психологи оказывают помощь, ориентируясь на иерархию потребностей, учитывая, что основным является удовлетворение базовых витальных потребностей;

- экстремальные психологи вынуждены работать как с отдельным человеком, так и с группой, которые в силу определенных обстоятельств переживают исключительно негативные эмоции. В нашем случае психологическую помощь может потребоваться не только жене погибшего полицейского, но и другим членам семьи [12].

При оказании экстренной психологической помощи необходимо помнить, что люди, которые попали в чрезвычайную ситуацию, страдают, как правило, от следующих факторов экстремальной ситуации:

1. Внезапность. Чем менее ожидаемой является событие, тем более трагическими является ее последствия для пострадавших.

2. Отсутствие опыта переживания чрезвычайной ситуации. Поскольку бедствия и чрезвычайные ситуации с потерей личного состава в условиях мирного времени происходят достаточно редко, люди, не имея соответствующих умений, знаний и навыков получают определенный опыт непосредственно в момент стресса.

3. Дезорганизация деятельности, нарушение контроля. Экстремальные условия полностью или частично дезорганизуют психику человека, нарушают восприятия и способность адекватно оценивать то, что происходит, а тем более, контролировать это.

4. Горе и утрата. Играют роль самостоятельных факторов, которые консолидируют переживания.

5. Столкновение со смертью. У тех, кто в условиях реальной угрозы пережил «встреча» со смертью, труднее чем у других проходит восстановительный период.

6. Необходимость принимать решения. Такая необходимость возникает рано или поздно, ведь потеря близкого человека - это еще и потеря определенного имущественного, физического, социального статуса и одновременно приобретение другой социальной роли, с определенным кругом задач и обязанностей.

7. Необходимость «реадаптироваться от экстремальных форм адаптации и интегрироваться в жизнь» [12, с. 159]. Человеку, который пережил масштабную чрезвычайную ситуацию, нужно осознать и принять то, что с ним случилось, какие изменения с ним произошли. В этом случае ему необходимо будет приспособиться к новым условиям жизнедеятельности, научиться жить с новым мировосприятием и новым опытом.

Учитывая эти факторы, психологи должны оказывать помощь исключительно в плоскости пережитой человеком стрессовом события и использовать для этого методы, которые являются соответствующими ситуации и психологического состояния человека. 
Н. Лунченко и И. Малкина-Пых указывают, что «в зависимости от срока предоставления помощи и задач, которые должны быть решены, можно выделить экстренную, краткосрочную и пролонгированную психологическую помощь» $[10$, с.24].

Экстренная помощь оказывается в первые несколько дней после травмирующего события, а также при проявлениях острой симптоматики, возникающей в результате воздействия дополнительных стресс-факторов.

Следующие несколько недель, а в некоторых случаях и месяцев, осуществляется краткосрочная помощь. В случае невозможности предоставить такую помощь своевременно, в дальнейшем ее предоставляют отсрочено. Но это требует больше времени и эффект от такой помощи несколько ниже.

Пролонгированная помощь предоставляется в течение нескольких лет после психологической травмы.

Сразу отмечаем, что такое разделение является условным и при практическом применении программ психологической реабилитации указанные виды помощи пересекаются. Так, например, экстренная помощь, предоставляемая на кризисном этапе, сразу после травмирующего события, применяется на этапе стабилизации, а также при проявлениях патологических реакций. На этапе стабилизации внедряется краткосрочная помощь и применяется в течение реабилитации. Что касается пролонгированного помощи, то она начинает предоставляться на этапе восстановления и не прекращается до полной интеграции. Пролонгированная помощь может продолжаться более двух лет. [10 с.25].

На исследованиях Е. Линдеманна сформировалась концепция адаптивных и неадаптивных способов реакции на стресс-факторы. Взаимодействие человека с травмирующим событием (в основном - эмоциональные реакции и устойчивые образцы поведения) оказывает значительное влияние на дальнейшее развитие личности и на образ его жизни. Восприятие ситуации, превышающей психические и физические возможности, влияет на продвижение к обретению целостности, или наоборот стагнации или даже дезинтеграции. [17].

Е. Линдеманн и Дж. Каплан, разрабатывая различные программы помощи людям, которые переживают кризис вследствие психологической травмы, делали акцент на быстром преодолении острых переживаний в первые шесть недель. Главная задача психолога обеспечить эмоциональную поддержку.

Такой вид помощи определяют как кризисное вмешательство или кризисная интервенция, и направлена она на «возвращение человека к адаптивному уровню функционирования, предотвращения психопатологии, снижение негативного воздействия травматического события» [9, с. 36].

Основой кризисного вмешательства техники превентивной психиатрии, предложенные в середине XX века Дж. Капланом, американским психологом и психиатром. Они направлены на предупреждение психических расстройств у людей, переживших тяжелые потери. Впоследствии идеи и практический опыт Дж. Каплана получили развитие и в настоящее время кризисное вмешательство рассматривается как комплексный подход, а не самостоятельная теория, основанная на принципах краткосрочной когнитивной терапии, психодинамической теории, теории социального научения (бихевиористский направление) и теории систем.

В эмпирических исследованиях реакции на травмирующие события Е. Линдеманн обратил внимание на развитие психологических и психосоматических проблем. Его работы показывают, что в случае своевременной помощи, человек не закрывается в себе, а контактируя с окружающими, выражает свои чувства и эмоции, переживая, таким образом, тяжелые события. В случае возражения своих реакций и неадекватного восприятия своего психологического состояния возможно возникновение патологических реакций, в частности, хронической депрессии, чувство безнадежности, страха, чувства вины и соматические проявления [18].

Различным фазам кризисного состояния после травмирующего события соответствуют разные реакции. В первой фазе, соответственно исследованиям Д. Агилера и Дж. Мессик, человек, столкнувшись со стрессовой событием, чувствует растущее напряжение, которое мешает организовать целесообразные действия по решаемой проблемы, а это, в свою очередь, приводит к нарастанию напряжения. Вторая фаза предполагает привлечение различных копингстратегий и активизацию внешних и внутренних ресурсов. Если эти усилия не приводят к изменениям в отношении к событию, в отношении к себе и к окружающим, то на третьей фазе возникает дезориентация личности, которая может проявиться в депрессии, импульсивном поведении и аутодеструктивных действиях [16]. 
В мировой психологической практике работы с экстремальными ситуациями применяются кризисные интервенции, разработанные Е. Линдеманн и Дж. Каплан. Интервенция состоит из четырех фаз, которые, как правило, пересекаются и не является строго последовательными. Это непосредственно оценка личности и ее психического состояния, выбор терапевтической интервенции, интервенция, разрешения кризиса и планирование будущих действий [8, с.94].

Ю. Г. Овчинникова предлагает в своем исследовании следующее понимание данных стадий:

На стадии оценки выясняется «текущее состояние человека и его способность справиться с ситуацией ... скорее выдержать ситуацию» [8, с. 95].

На этапе формирования терапевтической интервенции необходимо рассмотреть жизненные обстоятельства человека, внутренние ресурсы, а также влияние психического состояния на отношения с окружающими. Также важно на данном этапе дать возможность личности выразить свои чувства и осознать глубинные переживания.

Следующая стадия - интервенция, которая должна быть своевременной. Медлительность в оказании помощи снижает эффективность вмешательства и удлиняет деструктивную фазу кризиса. Но также не желателен и очень быстрый переход к оказанию помощи. Преждевременное вмешательство препятствует активации внутренних ресурсов личности и конструктивной работе кризиса.

На этапе интервенции человек уже чувствует некоторое облегчение и осмысливает произошедшее, начинает наблюдать за тем, что происходит, но еще не осознает глубинную взаимосвязь между травмирующим событием и собственным состоянием. В экстремальной ситуации можно исследовать различные части личности - некоторые окажутся беспомощными и напуганными, а другие проявляют силу и сохраняют мужество, опыт прохождения кризисных состояний.

«На стадии разрешения кризиса происходит резюмирования личностных изменений, подчеркивание новых умений по преодолению кризисного состояния, а также разработка методов самопомощи при новых травмирующих событиях». Происходит процесс реинтеграции, то есть «объективное и субъективное понимание события того, что произошло, высвобождение эмоций и принятия кризисной ситуации» $[9$, с.95].

П. Якобсен, сторонник экзистенциального направления в психологии, убежден, что кризисная интервенция может применяться только в начальном периоде после потери. «Она может принять форму конфронтации человека, переживающего горе, с ее потерей с целью выражения чувств, а также форму решительного вмешательства в общую жизненную ситуацию человека» [15]. Также он считает, что любой кризис несет в себе потерю. Реакцией на потерю является скорбь, и человек, благодаря этой скорби пытается, насколько это возможно, примириться с потерей и постепенно снова начать радоваться жизни.

Мы никогда не можем быть подготовлены к потере, такое событие всегда неожиданно. Как заметил М. Булгаков в своем известном романе «Мастер и Маргарита» - «да, человек смертен, но это было бы еще полбеды. Плохо то, что он иногда внезапно смертен, вот в чем штука» [3]. С потерей близкого человека мы теряем не только отношения со значимым человеком, но и часть себя, которая была связана с этим человеком. Е. Ильин замечает, что с «потерей близкого человека теряется роль отца, матери, сына, друга и т.д., следовательно, происходит уничтожение привычных функциональных завязок. Кроме того, не могут быть осуществлены намеченные совместные планы, довольны желания, связанные с этим человеком» [6, с.173].

Почти такого мнения придерживаться Отто Болноу об утрате одного из супругов - «в любящем сосуществовании вы создаете пространство друг для друга и строите общее пространство. Если другой человек умирает, общее пространство разрушается. Тот, кто пережил потерю, не может жить в своем мире так, как раньше. Таким образом, смерть любимого человека является потерей существования. Личность уменьшается. Смерть любимого является частью собственной смерти» [15].

Таким образом, утрата всегда выбивает человека из привычной колеи бытия. «В нормальном варианте человек, переживший утрату, впоследствии приходит от вызванного ею потрясения и начинает снова жить полноценной жизнью. В патологическом же варианте переживания горя остается нерешенным, незавершенным и выливается в различные психологические проблемы, приводит к той или иной форме дезадаптации» [13, с.10].

Вопрос адаптивности и дезадаптивности изучался на протяжении апробации программы психологического сопровождения жен погибших правоохранителей в том числе и с помощью 
методики диагностики социально-психологической адаптащии К. Роджерса-Р. Даймонд (СПА). Предложенная методика предметно ориентирована на изучение особенностей социальнопсихологической адаптации и связанных с этим черт личности. В качестве диагностического инструментария шкала СПА показала высокую способность в распознавании состояний адаптации - дезадаптации, особенностей представления о себе, а также анализе модели взаимодействия с социальным окружением.

Эмпирическая база исследования включает обобщенные результаты опроса 240 жен погибших правоохранителей, для определения с одной стороны необходимости психологической помощи и готовности его принять с другой стороны; в пролонгированной программе психологического сопровождения, которая имеет целью помочь человеку пережить утрату и принять новую реальность [11], принимали участие 32 женщины, жены погибших правоохранителей, срок вдовства до года, которые заявили о желании получить психологическую помощь (экспериментальная группа - ЭГ) и 34 человека составили контрольную группу (КГ).

Анализ результатов исследования по методике соииально-психологической адаптации К. Роджерса - Р. Даймонда.

Целью использования этой методики было исследование способности личности к гармоничной жизнедеятельности в обществе, которая заключается в желании и необходимости удовлетворять свои потребности в соответствии с требованиями социума, и дальнейшее использование этих данных для формирования психокоррекционной программы.

Полученные результаты свидетельствуют о том, что общий уровень социальнопсихологического состояния находится в пределах нормы. В то же время в обеих группах и при первом тестировании, и при ретесте показатели расположены от нижнего порога к верхнему. Более выраженное улучшение результатов наблюдается в группе, которая получила психологическую помощь.

Анализ полученных данных начинается с уровня искренности и открытости, который интерпретируется по шкале «ложь $+/$-». В нашем исследовании при первом тестировании $15 \%$ полученные данные менее, чем предложенная норма 6 человек в ЭГ и 4 человека в КГ. Результаты тестов этих респондентов не учитывались. Таким образом, в первом тестировании обрабатывались результаты ответов 56 респондентов двух групп. При ретесте показатели по данной шкале в пределах нормы. Обрабатывались результаты всех участников опроса. При ретест показатели по данной шкале в пределах нормы. То есть наблюдается открытость в раскрытии проблем, отсутствие сознательного намерения в подаче некорректной информации.

Показатели по шкале «адаптация» находятся в пределах нормы, что свидетельствует о приспособленности человека к взаимодействию с окружающими в системе межличностных отношений. Тенденция к совпадению целей и ценностных ориентаций с результатом, который достигается в процессе коммуникации. Поступки соответствуют намерениям, замыслы совпадают с воплощением. Данные по шкале «дезадаптация» также в пределах нормы. Наблюдается дисгармония в принятии решения, может быть следствием наличия двух и более равнозначных целей или сфер требующие внимания. Различия по шкале «адаптация» выявлены на уровне статистической тенденции: в ЭГ разница составляет Md (Mean Difference) $=11,75$, в КГ $\mathrm{Md}=6,4$, что свидетельствует о росте уровня адаптивности личности (таблица 1 ). Разница между двумя группами по t-критерию $=0,464$ (таблица 2). Данные по шкале «дезадаптация» также изменились, в ЭГ $\mathrm{Md}=4,75$, в КГ $\mathrm{Md}=6,0$, разница между двумя группами по $\mathrm{t}$ критерию $=0,339$.

Данные по шкале «принятие себя» в рамках предложенной нормы, что свидетельствует о положительной оценке своих личностных качеств. Различия в ЭГ $\mathrm{Md}=0,25$, в $\mathrm{K} \Gamma \mathrm{Md}=0,8$, разница между двумя группами по t-критерию $=0,392$. Результаты по шкале «неприятие себя» также в пределах нормы, в редких случаях ниже нормы, что свидетельствует о критическом отношении к своим личностных черт. Различия в ЭГ $\mathrm{Md}=-2,75$, в КГ $\mathrm{Md}=-3,2$, разница между двумя группами по t-критерию $=-0,413$. 
Таблица 1. Показатели разницы между тестом и ретестом для ЭГ и КГ.

\begin{tabular}{|c|c|c|c|c|c|c|c|c|}
\hline \multirow[t]{2}{*}{ Шкалы } & \multicolumn{4}{|c|}{ ЭГ - разница тест-ретест } & \multicolumn{4}{|c|}{ КГ-разница тест-ретест } \\
\hline & $\begin{array}{c}\text { Среднее } \\
\text { значение }\end{array}$ & $\begin{array}{l}\text { Разница } \\
\text { значений }\end{array}$ & $\mathbf{t}$ & $\mathbf{p}$ & $\begin{array}{c}\text { Среднее } \\
\text { значение }\end{array}$ & $\begin{array}{c}\text { Разница } \\
\text { значений }\end{array}$ & $\mathbf{t}$ & $\mathbf{p}$ \\
\hline Адаптивность & $131,25 / 143,0$ & $-11,75$ & $-2,668$ & 0,076 & $132,2 / 138,6$ & $-6,4$ & $-1,009$ & 0,370 \\
\hline Дезадаптивность & $79,0 / 83,75$ & $-4,75$ & $-0,927$ & 0,422 & $82,6 / 88,6$ & $-6,0$ & $-1,443$ & 0,223 \\
\hline Лживость "-" & $19,75 / 20,50$ &,- 75 &,- 333 & 0,761 & $19,0 / 20,8$ & $-1,8$ & $-0,885$ & 0,426 \\
\hline Лживость "+" & $12,75 / 16,0$ & $-3,25$ & $-2,263$ & 0,109 & $14,0 / 15,4$ & $-1,4$ & $-0,649$ & 0,552 \\
\hline Принятие себя & $47,25 / 47,0$ & 0,25 & 0,047 & 0,966 & $46,0 / 45,2$ & 0,8 & 0,191 & 0,858 \\
\hline Непринятие себя & $10,75 / 13,5$ & $-2,75$ & $-0,641$ & 0,567 & $11,6 / 14,8$ & $-3,2$ &,- 954 & 0,394 \\
\hline Принятие других & $19,0 / 24,0$ & $-5,0$ & $-2,357$ & 0,100 & $19,0 / 23,6$ & $-4,6$ & $-2,720$ & 0,053 \\
\hline $\begin{array}{l}\text { Непринятие } \\
\text { других }\end{array}$ & $19,0 / 16,25$ & 2,75 & 1,718 & 0,184 & $19,8 / 17,8$ & 2,0 & 1,380 & 0,240 \\
\hline $\begin{array}{l}\text { Эмоциональный } \\
\text { комфорт }\end{array}$ & $26,5 / 30,5$ & $-4,0$ & $-0,819$ & 0,473 & $25,2 / 29,0$ & $-3,8$ & $-1,003$ & 0,372 \\
\hline $\begin{array}{l}\text { Эмоциональный } \\
\text { Дискомфорт }\end{array}$ & $17,25 / 16,5$ & 0,75 & 0,365 & 0,740 & $17,6 / 18,6$ & $-1,0$ & $-0,423$ & 0,694 \\
\hline $\begin{array}{l}\text { Внутренний } \\
\text { контроль }\end{array}$ & $55,5 / 60,25$ & $-4,75$ & $-0,864$ & 0,451 & $57 / 60,4$ & $-3,4$ & $-0,761$ & 0,489 \\
\hline $\begin{array}{l}\text { Внешний } \\
\text { контроль }\end{array}$ & $20,25 / 24,0$ & $-3,75$ & $-5,000$ & 0,015 & $20,8 / 25,2$ & $-4,4$ & $-5,047$ & 0,007 \\
\hline Доминирование & $9,5 / 12,0$ & $-2,5$ & $-1,014$ & 0,385 & $9,6 / 10,8$ & $-1,2$ & $-0,519$ & 0,631 \\
\hline Ведомость & $12,0 / 13,5$ & $-1,5$ & $-1,000$ & 0,391 & $14 / 13,6$ & 0,4 & 0,180 & 0,866 \\
\hline $\begin{array}{l}\text { Экспатизм } \\
\text { (уход в себя) }\end{array}$ & $18,5 / 15,5$ & 3,0 & 4,243 & 0,024 & $16,6 / 14,4$ & 2,2 & 2,269 & 0,086 \\
\hline
\end{tabular}

Полученные данные по шкале «принятие других» и «неприятие других» также в пределах нормы, что свидетельствует об умеренной терпимость к людям, способность давать как положительные, так и отрицательные оценки личности. Различия по шкале «принятие» в ЭГ $\mathrm{Md}=-5,0$, в КГ $\mathrm{Md}=-4,6$, разница между двумя группами по t-критерию $=0,198$ на уровне статистической достоверности различий. По шкале «неприятие» различия в ЭГ $\mathrm{Md}=2,75$, в КГ $\mathrm{Md}=2,0$, разница между двумя группами незначительная - по t-критерию $=0,325$.

«Эмоциональный комфорт» в пределах нормы, показывает адекватный уровень определенности в своем эмоциональном отношении к окружающим предметам и явлениям. Различия в ЭГ $\mathrm{Md}=-4,0$, в КГ $\mathrm{Md}=-3,8$, разница между двумя группами по t-критерию $=0,321$. Данные по шкале «эмоциональный дискомфорт» в рамках верхнего порога, что свидетельствует о наличии напряжения, беспокойства, недовольство окружающей действительностью. Различия в ЭГ $\mathrm{Md}=0,75$, то есть показатели уменьшились, в КГ $\mathrm{Md}=-1$, то есть показатели увеличились, разница между двумя группами по t-критерию $=0,749$.

Самые важные изменения в двух группах зафиксировано по шкале «внешнего контроля». Обычно экстернальный контроль свидетельствует о доминировании склонности личности приписывать причины происходящего внешним факторам, но в нашем случае причина стрессового состояния из-за потери близкого человека является действительно внешним фактором. Одиночество и изменение условий жизнедеятельности - это не сознательный выбор, а стечение обстоятельств. Поэтому вполне нормально, что при тестировании данные по этой шкале были вне нормы. При ретесте выявлено, что при статистической достоверности $\mathrm{p}=0,007$ в КГ и $\mathrm{p}=0,015$ в ЭГ произошли изменения, данные в КГ $\mathrm{Md}=-4,4$ и в ЭГ $\mathrm{Md}=-3,75$, что свидетельствует о росте влияния внешних факторов. Различия между двумя группами незначительные, в пределах статистической тенденции данные по $t$-критерию $=0,188$. Что касается внутреннего контроля, то показатели по двум группам в пределах нормы и выше верхнего порога. Это свидетельствует о способности брать 
на себя ответственность. Изменения между тестом и ретест в пределах статистической тенденции в ЭГ данные представлены $\mathrm{Md}=-4,75$, а в КГ данные $\mathrm{Md}=-3,4$, различия между двумя группами по t-критерию $=0,017$.

Анализ данных по шкале «доминирование» свидетельствует об умеренном желание воздействовать на других, настаивать на правильности своей позиции и убеждать в своем мнении. Изменения между формирующим и констатирующим экспериментом в пределах статистической тенденции в ЭГ данные представлены $\mathrm{Md}=-2,5$, а в КГ $\mathrm{Md}=-1,2$, различия между двумя группами по t-критерию $=0,678$, то есть в ЭГ уровень доминирования стал выше. Полученные результаты по шкале «ведомость» свидетельствуют об умеренной и адекватной податливости внешнему воздействию, которая в ряде случаев может сочетаться с определенной уступчивостью. Все показатели в пределах статистической тенденции, различия в ЭГ $\mathrm{Md}=-1,5$, в КГ $\mathrm{Md}=0,4$, разница между двумя группами по t-критерию $=0,067$.

Таблица 2. Результаты сравнения средних значений ЭГ и КГ при повторном тестировании.

\begin{tabular}{|c|c|c|c|c|c|c|c|}
\hline \multirow[t]{2}{*}{ Шкалы } & \multicolumn{3}{|c|}{ Ретест разница ЭГ и КГ } & \multirow[t]{2}{*}{ Шкалы } & \multicolumn{3}{|c|}{ Ретест разница ЭГ и КГ } \\
\hline & $\begin{array}{l}\text { Разница } \\
\text { значений }\end{array}$ & $\mathbf{t}$ & $\mathbf{p}$ & & $\begin{array}{l}\text { Разница } \\
\text { значений }\end{array}$ & $\mathbf{t}$ & $\mathbf{p}$ \\
\hline Адаптивность & 4,4 & 0,464 & 0,657 & $\begin{array}{l}\text { Эмоциональный } \\
\text { комфорт }\end{array}$ & 1,5 & 0,321 & 0,757 \\
\hline Дезадаптивность & $-4,85$ & $-0,339$ & 0,745 & $\begin{array}{l}\text { Эмоциональный } \\
\text { дискомфорт }\end{array}$ & $-2,1$ & $-0,749$ & 0,478 \\
\hline Лживость "-" & $-0,3$ & $-0,188$ & 0,857 & $\begin{array}{l}\text { Внутренний } \\
\text { контроль }\end{array}$ & $-0,15$ & $-0,017$ & 0,987 \\
\hline Лживость "+" & 0,6 & 0,360 & 0,729 & $\begin{array}{l}\text { Внешний } \\
\text { контроль }\end{array}$ & $-1,2$ & $-0,188$ & 0,856 \\
\hline Принятие себя & 1,8 & 0,392 & 0,707 & Доминирование & 1,2 & 0,678 & 0,520 \\
\hline Непринятие себя & 1,1 & 0,413 & 0,692 & Ведомость & $-0,1$ & $-0,067$ & 0,948 \\
\hline Принятие других & 0,4 & 0,198 & 0,848 & $\begin{array}{l}\text { Экспатизм } \\
\text { (уход в себя) }\end{array}$ & 1,1 & 0,364 & 0,727 \\
\hline $\begin{array}{l}\text { Непринятие } \\
\text { других }\end{array}$ & $-1,55$ &,- 325 & 0,755 & & & & \\
\hline
\end{tabular}

Показатели последней шкалы («эскапизм») также претерпели изменения. Различия в ЭГ $\mathrm{Md}=3,0$, в КГ $\mathrm{Md}=2,2$, разница между двумя группами по t-критерию $=0,364$. То есть показатели в двух группах уменьшились, а именно уменьшился уровень избегание проблемных ситуаций, уход от них. В ЭГ результаты более значительны.

Статистически значимые результаты в ЭГ наблюдаются в изменениях по шкале «внешний контроль» - разница значения по t-критерию $=-5,0(p=0,015)$ и по шкале «эскапизм» - разница значения по t-критерию $=4,243(p=0,024)$ (Таблица 3). В КГ статистично значимые результаты отмечены по шкале «принятие других» - разница значения по t-критерию $=-2,72$ $(p=0,05)$ и «внешний контроль» - разница значения по t-критерию $=-5,047(p=0,007)$. Остальные изменения на уровне статистической тенденции.

Выводы. Опираясь на научные теоретические и практические достижения отечественных и зарубежных ученых, результаты собственного исследования, вполне уместно сделать вывод о целесообразности оказания психологической помощи при утере, применяя принципы экстремальной психологии, а именно - своевременности, инициативности со стороны психологических служб, с учетом иерархичности личных проблем. Опыт взаимодействия человека с травмирующим событием, в дальнейшем оказывает значительное влияние на развитие личности и на ее способ адаптации к новым условиям жизни. Экспериментальное исследование показывает, что при предоставлении системной психологической помощи наблюдается тенденция к росту показателей адаптивности и эмоционального комфорта, уменьшения уровня избежание проблемных ситуаций, уход от них.

Перспективу дальнейших исследований видим в разработке таких вопросов, как совершенствование программ психологического сопровождения семей погибших правоохранителей и организация социально-психологической работы с семьями правоохранителей. 


\section{REFERENCES}

1 Bayer O. O. Zhittevi krizi osobistostI: navchalniy posIbnik / O. O. Bayer. - D.: Vid-vo DnIpropetr. nats. un-tu, 2010. - $244 \mathrm{~s}$.

2 Bondarenko A. F. Psihologicheskaya pomosch: teoriya i praktika. [3-e izd., ispr. i dop.]. M.: Klass, 2001. $336 \mathrm{~s}$.

3 Bulgakov M. Mayster I Margarita: roman. [per. z ros. M. BIlousa; peredmova I primItki N. P. Evstaf'EvoYi]. HarkIv: Follo, 2006. 415 s. (B-ka svIt. 1It.). URL: http://knigger.org/bulgakov/masteri-margarita/lang/ua/\#/page/139

4 Ivanyushina P. V. Psihologicheskaya pomosch kak osnova transformatsii lichnosti v situatsii gorya utratyi. Teoriya i praktika obschestvennogo razvitiya. 2015. \# 15 S. 169-171.

$5 \quad$ Ilin E. P. Emotsii i chuvstva. Sankt-Peterburg: Piter, 2001. 752 s. (Seriya: Mastera psihologii).

6 Ovchinnikova Yu. G. K probleme interventsiy v situatsii krizisa lichnosti: ot teorii k praktike. Kulturnoistoricheskaya psihologiya. 2010. \# 3. C. 93-98. URL: http://psyjournals.ru/kip/2010/n3/30828.shtml

7 PsihosotsIalna dopomoga $v$ robotI z krizovoyu osobistIstyu: navch. posIb. [nauk. red. ta kerIvnik problem. grupi L. M. Volnova]. KiYiv: NPU ImenI M. P. Dragomanova, 2012. 275 s.

8 SotsIalno-pedagogIchna ta psihologIchna dopomoga sIm'yam z dItmi v perIod vIyskovogo konflIktu: navch.-metod. posIb. KiYiv: Agentstvo "UkraYina", 2015. 176 s.

9 Ryibyik L.A. Osnovnyie etapyi programmyi psihologicheskoy pomoschi pri perezhivanii utratyi. Mezhdunarodnyiy nauchno-prakticheskiy zhurnal «Pravo i Zakon». 2017. \# 4. S. 75-79.

10 TImchenko O. V., Hristenko V. E., OnIschenko N. V.Chi potrIbnI UkraYinI fahIvtsI z psihologIYi ekstremalnih situatsIy? Problemi ekstremalnoYi ta krizovoYi psihologIYi: zb. nauk. prats. HarkIv, 2010. Vip. 8. S. 154-162.

11 Shefov S. A. Psihologiya gorya. Sankt-Peterburg: Rech, 2006. 144 s.

12 Epikur. Glavnyie myisli. HHHIH. Materialistyi Drevney Gretsii. Sobrinae tekstov Geraklita, Demokrita i Epikura. M., 1955. S. 213-218.

13 Yakobsen B. Zhiznennyiy krizis v ekzistentsialnoy perspektive: mogut li travma i krizis rassmatrivatsya kak pomosch v lichnom razvitii? [per. s angl. M. Bagdonene]. Ekzistentsialnoe izmerenie v konsultirovanii i psihoterapii: sb. [sost. Yu. Abakumova-Kochyunene]. Birshtonas-Vilnyus, 2005. T. 2. S. 101-112. URL: http:// hpsy.ru/public/ x2267.htm

14 Aguilera D., Messick J. Crisis Intervention: Theory and Methodology. Sarnt Zouis Mosby, 1982. 4th - Tsit. $\mathrm{Za}$ «»Perspektivnyie napravleniya psihologicheskoy nauki»

15 Behavioral concepts and nursing intervention. Philadelphia: J.B. Lippincott. Carlson, C.E. and Blackwell, B. (Eds.). (1978).

16 Lindemann E. Symptomatology and management of Acute Grief // American Journal of Psychiatry. 1944. Vol. 101. 